\title{
Comparative evaluation of laparoscopic liver resection for posterosuperior and anterolateral segments
}

\author{
Airazat M. Kazaryan • Bård I. Røsok • \\ Irina Pavlik Marangos • Arne R. Rosseland • \\ Bjørn Edwin
}

Received: 27 May 2010/ Accepted: 9 June 2011/Published online: 7 July 2011

(c) The Author(s) 2011. This article is published with open access at Springerlink.com

\begin{abstract}
Background Totally laparoscopic liver resection of lesions located in the posterosuperior segments is reported to be technically challenging. This study aimed to define whether these technical difficulties affect the surgical outcome.

Methods A total of 220 patients underwent laparoscopic liver resection during 244 procedures from August 1998 to December 2010. The patients who underwent primary minor single liver resection for malignant tumors affecting either posterosuperior segments $1,7,8$, and, 4 a (group 1) or anterolateral segments $2,3,5,6$, and $4 \mathrm{~b}$ (group 2) were included in the study. Seventy-five procedures found to be eligible for the study, including 28 patients in group 1 and 47 patients in group 2. Intraoperative unfavorable incidents were graded on the basis of the Satava approach and postoperative complications were graded in agreement with the Accordion classification.
\end{abstract}

Presented at the 18th EAES Congress, June 16-19, 2010, Geneva, Switzerland.

A. M. Kazaryan $(\square)$. I. P. Marangos · B. Edwin

Interventional Centre, Rikshospitalet, Oslo University Hospital Health Trust, 0027 Oslo, Norway

e-mail: kazaryan@gmail.com

A. M. Kazaryan · B. I. Røsok · A. R. Rosseland · B. Edwin Department of Gastrointestinal and Hepatobiliary Surgery, Rikshospitalet, Oslo University Hospital Health Trust, 0027 Oslo, Norway

A. M. Kazaryan · I. P. Marangos · B. Edwin Institute of Clinical Medicine, Medical Faculty, University of Oslo, 0316 Oslo, Norway

A. M. Kazaryan

Surgical Department, Drammen Hospital, 3004 Vestre Viken Health Trust, Drammen, Norway
Results The operative time (median, $127 \mathrm{~min}$ ) and blood loss (median, $200 \mathrm{ml}$ ) were equivalent in the two groups. The rates for blood transfusions and intraoperative accidents did not differ statistically between the groups. A tumor-free margin resection was achieved in $94.7 \%$ of the procedures, equivalently in both groups. The postoperative course was similar in the two groups. Postoperative complications developed in 2 cases (7.1\%) in group 1 and 2 cases $(4.3 \%)$ in group $2(p=0.626)$. The median hospital stay was 2 days in both groups.

Conclusions Laparoscopic liver resection for lesions located in posterosuperior segments represents certain technical challenges. However, appropriate adjustment of surgical techniques and optimal patient positioning enables the laparoscopic technique to provide safe and effective parenchyma-sparing resections for lesions located in both posterosuperior and anterolateral segments.

Keywords Anterolateral segments - Laparoscopic liver resection $\cdot$ Posterosuperior segments

Treatment of pathologic liver lesions is a fast-developing area within current surgical practice [1]. In the early 1990s, Reich et al. [2] and Gagner et al. [3] reported the first cases of laparoscopic liver resection. Since that time, the feasibility and safety of this procedure have been documented in several reports [4-19]. Despite tremendous advancement in the field of laparoscopic hepatobiliary surgery related to both operative techniques and instrumentation, most laparoscopic liver resections still are mainly performed for easily accessible lesions [20].

Totally laparoscopic liver resection of posterosuperior segments are reported to be technically challenging [21]. Establishment of a good outcome after laparoscopic liver 
resection of lesions located in posterosuperior segments could stimulate a wider application of this patient friendly technique worldwide [22]. We aimed to define whether these technical difficulties affect clinical outcome in the expert hepatobiliary center.

\section{Materials and methods}

\section{Patients}

Rikshospitalet is a referral center for hepatobiliary procedures. A total of 220 patients underwent laparoscopic liver resection during 244 procedures from August 1998 to December 2010 at the Oslo University Hospital, Rikshospitalet. Our general experience and application of laparoscopic liver resections in the treatment of patients with colorectal liver metastases was reported earlier [14, 23].

Patients who underwent primary minor liver resection of malignant tumors affecting either posterosuperior segments $1,7,8$, and 4a (group 1) or anterolateral segments 2, 3, 5, 6, and $4 \mathrm{~b}$ (group 2) were included in this study (Fig. 1). To ensure an appropriate comparison between these two groups of interest, the study excluded patients with benign lesions; patients who underwent either hemihepatectomy, left lateral lobectomy, or combined liver ablation procedures; patients who simultaneously underwent another major laparoscopic operation; and patients with lesions affecting both anterolateral and posterosuperior segments. Seventy-five procedures were found to be eligible for the study, including 28 patients in group 1 and 47 patients in group 2.

The indications for laparoscopic liver resection were similar to those for open liver resection with respect to preoperative assessment of liver function, type of liver resection, and postoperative care. The majority of liver tumors in both groups were colorectal metastases (Table 1). The patient demographic data were similar in the two groups (Table 2).

We used unified criteria to grade perioperative adverse events. Intraoperative unfavorable incidents were graded on the basis of the Satava approach to surgical error evaluation (Table 3 ) and postoperative complications were graded in agreement with the Accordion classification (Clavien-Dindo-Strasberg classification) [23-27].

The standard preoperative investigations included liver imaging (spiral computed tomography $[\mathrm{CT}]$ and contrast ultrasonography as routine, and magnetic resonance imaging [MRI] and positron emission tomography [PET]$\mathrm{CT}$ if required), chest imaging (plain X-ray or CT from 2005), and clinical biochemistry.

The patients received perioperative subcutaneous lowmolecular-weight heparin. Intravenous anesthesia was used. At the beginning of surgery, bupivacaine hydrochloride was injected at the trocar port sites. Postoperative analgesia consisted of a nonsteroidal antiinflammatory drug and intravenous paracetamol. Intravenous opioids, mainly by means of patient-controlled analgesia pump, were given if additional analgesia was required. Postoperative opioid administration was registered from the first postoperative day. The patients were encouraged to mobilize early and resume feeding as soon as it was tolerated. Tumor size was measured after specimen fixation in formaldehyde during the histopathologic analyses of the resected specimens.

For patients discharged to a local hospital, information about the postoperative course was retrieved and incorporated into the analyses of morbidity and hospital stay.

Fig. 1 Schematic view of liver segments. The continuous black line indicates a conventional division of the liver to posterosuperior segments 1,7 , 8 , and $4 \mathrm{a}$ and anterolateral segments $2,3,5,6$, and $4 \mathrm{~b}$

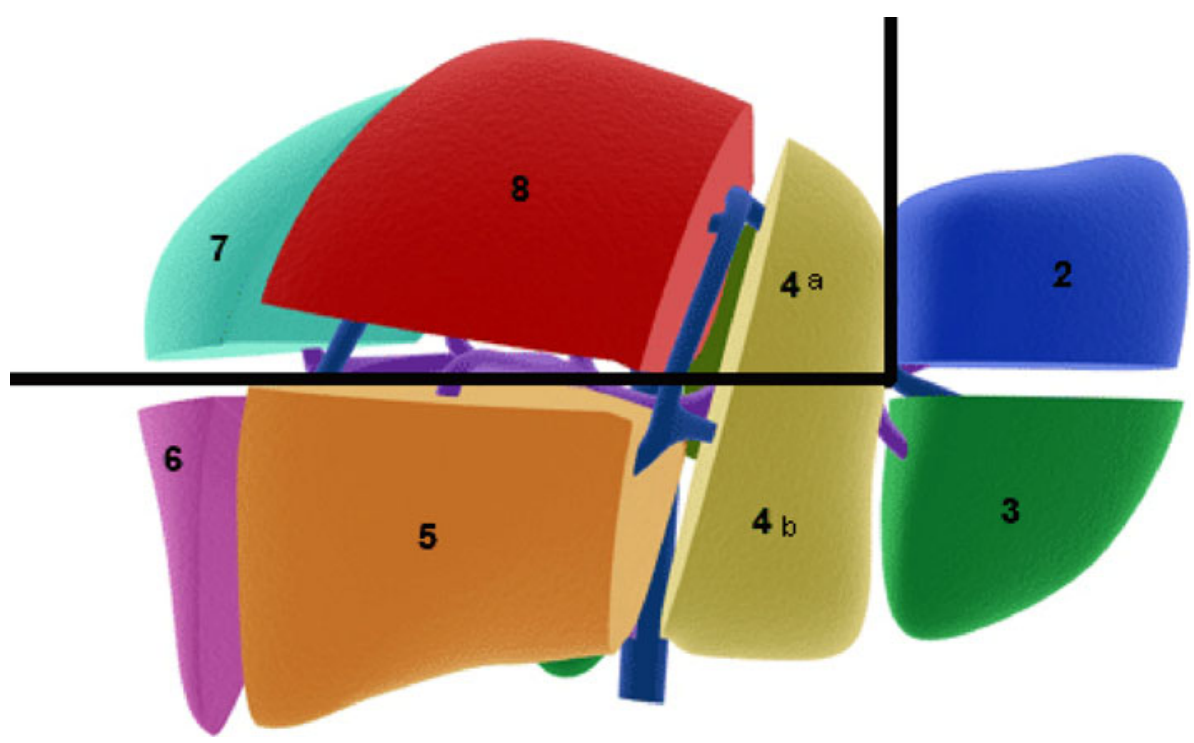


Table 1 Representation of indications for surgery

\begin{tabular}{llll}
\hline & Group 1 $(n=28)$ & Group 2 $(n=47)$ & Total $(n=75)$ \\
\hline Metastatic tumors & 28 & 43 & 71 \\
Colorectal adenocarcinoma & 24 & 36 & 60 \\
Anal squamous cell carcimoma & 1 & 1 & 2 \\
Pancreatic glucagonoma & 1 & - & 1 \\
Pancreatic adenocarcinoma & - & 1 & 1 \\
Lung adenocarcinoma & 1 & 1 & 2 \\
Melanoma (eye) & 1 & 1 & 1 \\
Carcinoid & - & 2 & 1 \\
Malignant hemangiopericytoma & - & 1 & 1 \\
Primary liver tumors: & - & 4 & 4 \\
Hepatocellular carcinoma & - & 3 & 3 \\
Cholangiocarcinoma & - & 1 & 1 \\
\hline
\end{tabular}

Table 2 Patient characteristics

\begin{tabular}{llllc}
\hline Parameters & Group 1 $(n=28)$ & Group 2 $(n=47)$ & $p$ Value & Total $(n=75)$ \\
\hline Age: years (range) & $68(43-82)$ & $62(35-88)$ & 0.155 & $65(35-88)$ \\
ASA score: $n$ (range) & $2(2-3)$ & $3(1-4)$ & 0.111 & $2(1-4)$ \\
Female/male & $16 / 12$ & $20 / 27$ & 0.242 & $36 / 39$ \\
Previous laparotomy: $n(\%)$ & $22(78.6 .1 \%)$ & $39(83.0 \%)$ & 0.636 & $62(82.7 \%)$ \\
\hline
\end{tabular}

Data are presented as median (range) or number $(\%)$

Table 3 Grading of unfavorable intraoperative incidents on the basis of the Satava approach to surgical error evaluation; adapted for liver surgery

Grade Definition of intraoperative incidents

1 Incidents managed without change of operative approach and without further consequences for the patient. It includes perforations of adherent or adjacent organs, minor change in intraoperative tactics, and cases with blood loss exceeding the normal range (corresponding to blood loss exceeding $1,000 \mathrm{ml}$ in case of liver resection)

2 Incidents with further consequences for the patient. It includes cases requiring limited resection of intraoperatively injured organs or cases with blood loss appreciably more than the normal range. (It corresponds to blood loss exceeding 2,000 $\mathrm{ml}$ in case of liver resection). It also includes cases requiring conversion to an open approach

3 Incident leading to significant consequences for the patient

Perioperative mortality was defined as death within 30 days or before hospital discharge.

\section{Techniques}

The extent of liver resection was not altered by the application of laparoscopic techniques. The surgical technique has been described in detail previously [14].

To reach the most problematic segments (7 and 8), four laparoscopic port sites usually were needed (Fig. 2). The patient's right abdominal side was elevated up to between $45^{\circ}$ and $60^{\circ}$. Usually, $12-\mathrm{mm}$ port sites were used to enable application of a wide range of laparoscopic instruments and devices. Patient positioning and trocar placement should be carefully adjusted to the tumor location and patient constitution.
The first port site was established by Edwin's techniques on the pararectal line $10 \mathrm{~cm}$ below the costal arch [28]. This port site was applied as the main site for a $30^{\circ}$ laparoscope. In very difficult cases (e.g., when the quality of the liver parenchyma prevented adequate mobilization of the right lobe), a flexible laparoscope (HD EndoEYE LTFVH; Olympus, Tokyo, Japan) was used.

After a concise evaluation of the abdominal wall in the area of the intended trocar placement, two other trocars were established lateral to the initial port site. The most lateral trocar was positioned immediately anterior to the right paracolic line to ensure a maximal posterior approach. These port sites were applied as main sites for the surgical handling of instruments. One additional port site was established in the medioclavicular line about $5 \mathrm{~cm}$ below the costal arch. This site was used mainly for variable 
Fig. 2 Approach to segment 8 .

A, B Computed tomography of a tumor in segment 8 with a vein branch in proximity requiring attention.

C Dissection. D Extracted specimen resulting from parenchyma-sparing resection. E Flexible laparoscope.

F Trocar positioning
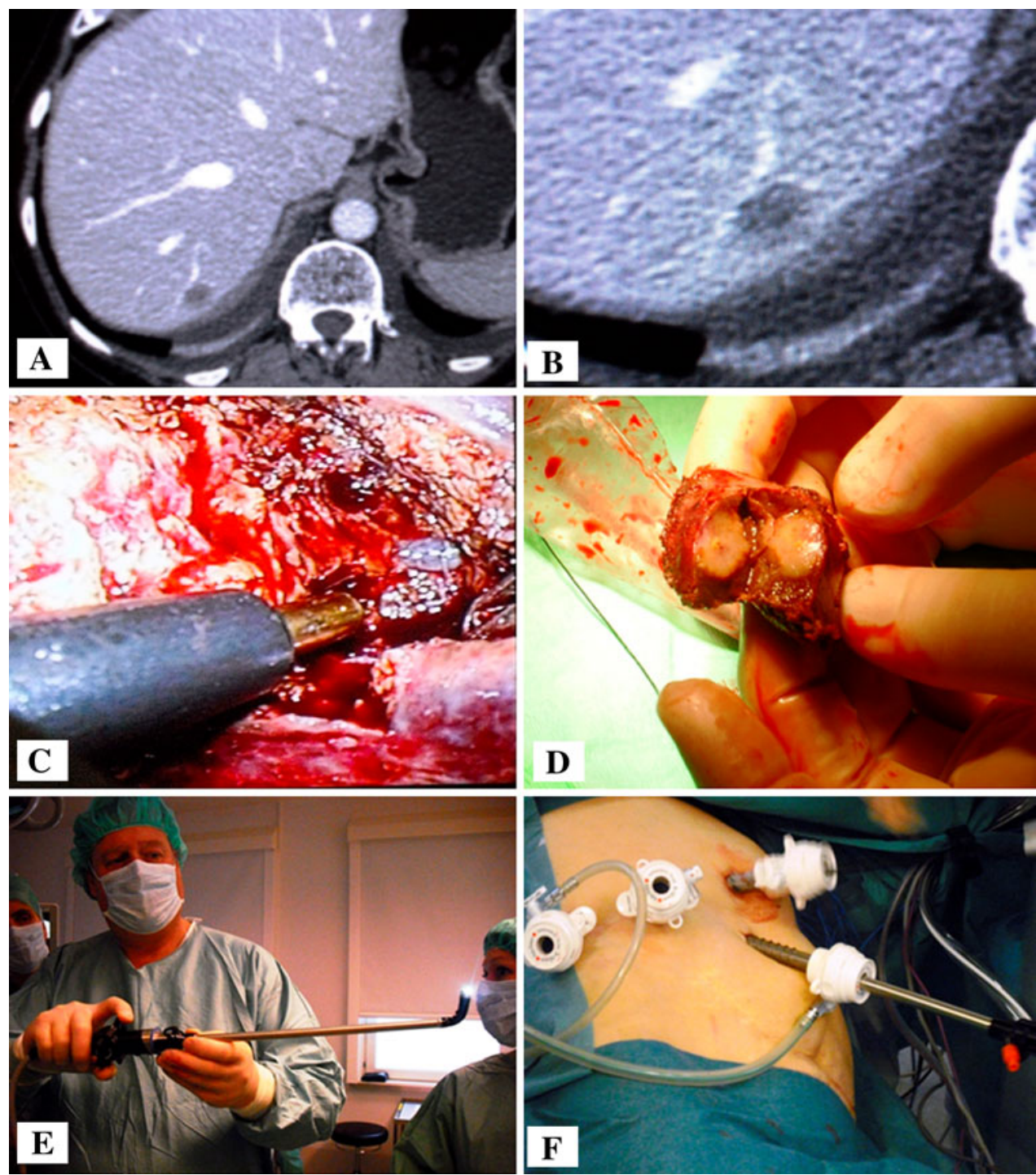

application of a five-blade liver retractor or for division of the anterior portion of the coronary ligament.

After division of adhesions due to previous abdominal surgery, the liver was thoroughly examined using laparoscopic ultrasonography with Doppler function. For exposure of lateral lesions in segment 8 and all lesions in segment 7 , the posterior portion of the right lobe was fully mobilized. The right liver was lifted anteriorly by the liver retractor, and both the right triangular ligament and the coronary ligament were properly divided. The right liver was meticulously dissected away from the caval vein upward to the right hepatic vein (approach to segments 7 and 8), and in selected cases, the middle hepatic vein (in case of approach to lesions in the most cranial part of segment 8) were visualized.

The short hepatic veins were transected by clips or Ligasure (Covidien, Norwalk, CT, USA). The resected liver was removed in one piece through an enlarged umbilical port incision using a $15-\mathrm{mm}$ pouch (EndoCatch; U.S. Surgical Corporation, Norwalk, CT, USA).

Statistical analysis

The major treatment outcomes were compared between groups 1 and 2. The data are presented as median (range) or number (percentage). Fisher's exact test or Pearson's chisquare test was applied to compare proportions between groups as appropriate. For comparison of continuous variables, the Mann-Whitney $U$ test was used.

The overall survival for patients with colorectal liver metastases was evaluated. The log-rank test was applied for comparison of survival between groups.

The median follow-up period was 18 months (range, 6-56 months) in group 1 and 26 months (range, 
5-121 months) in group $2(p=0.176)$. Follow up status (i.e., patient survival and tumor recurrence in the liver) was finally verified in May 2011.

\section{Results}

No conversions to open surgery occurred in either of the studied groups. The types of resections are presented in Table 4.

The operative time and blood loss were equivalent in the two groups (Table 5). The rate of blood transfusions and unfavorable intraoperative accidents did not differ statistically between the groups. One intraoperative accident occurred in group 1: a case of immoderate intraoperative bleeding $(1,700 \mathrm{ml}$, managed laparoscopically) in a patient with colorectal metastasis in segment 8 (Satava grade 1). Three intraoperative accidents occurred in group 2: a case of minor perforation to the small bowel during surgery (immediately sutured laparoscopically) in a patient with colorectal metastasis in segments 5 and 6 (Satava grade 1), a case of immoderate intraoperative bleeding $(2,000 \mathrm{ml}$, managed laparoscopically) in a patient with colorectal metastasis in segments 5 and $4 \mathrm{~b}$ (Satava grade 1), and a case of immoderate intraoperative bleeding $(2,500 \mathrm{ml}$, managed laparoscopically) in a patient with liver cirrhosis and hepatocellular carcinoma in segments 2 and 3 (Satava grade 2). Neither of the groups had perioperative mortality.

The median tumor size was similar in the two groups. No significant difference in weight or dimensions of the resected liver specimen was observed. Two cases in each

Table 4 Representation of resection types

\begin{tabular}{lc}
\hline Segments & No. of cases \\
\hline Group $1(n=28)$ & 13 \\
7 & 7 \\
8 & 3 \\
$4 \mathrm{a}$ & 2 \\
1 & 2 \\
7 and 8 & 1 \\
7,8, and $4 \mathrm{a}$ & \\
Group $2(n=47)$ & 11 \\
3 & 11 \\
6 & 5 \\
5 & 5 \\
$4 \mathrm{~b}$ & 3 \\
2 & \\
5 and 6 & 5 \\
5 and $4 \mathrm{~b}$ & 4 \\
2 and 3 & 2 \\
3 and $4 \mathrm{~b}$ & 1 \\
\hline
\end{tabular}

group had involvement of tumor tissue in the resection. For one additional case in each group, the resection margin was negative but less than $1 \mathrm{~mm}$. A tumor-free margin resection was achieved totally in $94.7 \%$ of the procedures of both groups (Table 6). The minimal distance from the resection line to the tumor tissue was significantly shorter in group 1 (median, $3 \mathrm{~mm}$ ) than in group 2 (median, $8 \mathrm{~mm})$.

The postoperative course did not differ statistically between the studied groups (Table 5). On the day of the operation, 70 (93.3\%) of the 75 patients began to drink (26 of the 28 patients in group 1 and 44 of the 47 patients in group 2). All the patients in both groups started to consume a solid diet on the first postoperative day. All the patients were transferred from the postoperative intensive care unit to the ordinary patient ward on the day of the operation. Only $14(50 \%)$ of the 28 patients in group 1 and 21 (44.7\%) of the 47 patients in group 2 required postoperative opioid administration.

Two postoperative complications (7.1\%) developed in group 1: biliary leakage managed by percutaneous drainage in a patient with colorectal metastasis in segments 7,8 , and 4a (readmitted for development of abscess, treated by antibiotics) and liver abscess in the area of liver resection managed by percutaneous drainage in a patient with pancreatic glucagonoma in segment 4a. Two complications (6.4\%) developed in group 2: bleeding at a trocar site of a patient with colorectal metastasis in segment 3 controlled by suture with the patient under local anesthesia and pneumonia and intraabdominal seroma (percutaneously drained) in a patient with colorectal metastasis in segments 5 and $4 b$.

In an additional case, diagnostic laparoscopy was applied on postoperative day 2 due to unconfirmed suspicion (occasioned by a sharp rise in C-reactive protein) of biliary leakage in a patient with metastasis of anal squamous cell carcinoma. The patient recovered uneventfully and was discharged on postoperative day 5. All postoperative complications corresponded to grade 3 of the Accordion classification.

The median postoperative hospital stay was 2 days in both groups. Of the 75 patients, $68(90.7 \%)$ were discharged to their private homes ( 25 of the 28 patients in group 1 and 43 of the 47 patients in group 2), whereas a smaller number were transferred to a local hospital, another hospital department, or a patient hotel for convalescence.

Tumor recurrence in the liver developed in $8(28.6 \%)$ of the 28 patients in group 1 after a median of 7 months (range, 4-8 months), and in $16(34 \%)$ of the 47 patients in group 2 after a median of 7 months (range, 2-25 months). The data on postoperative liver recurrence and overall survival did not differ statistically between the two groups ( $p=1.000$ and 0.332 respectively). 
Table 5 Surgical outcomes

\begin{tabular}{|c|c|c|c|c|}
\hline & Group $1(n=28)$ & Group $2(n=47)$ & $p$ Value & Total $(n=75)$ \\
\hline \multicolumn{5}{|l|}{ Intraoperative parameters } \\
\hline Intraoperative incidents: $n(\%)$ & $1(3.6)$ & $3(6.4)$ & 1.000 & $4(5.3)$ \\
\hline Operative time: $\min$ (range) & $125(50-336)$ & $130(50-315)$ & 0.891 & $127(50-336)$ \\
\hline Blood loss: ml (range) & $200(<50-1,700)$ & $200(<50-2,500)$ & 0.849 & $200(<50-2,500)$ \\
\hline Blood transfusions & $1(3.6)$ & $4(8.5)$ & 0.645 & $5(6.7)$ \\
\hline \multicolumn{5}{|l|}{ Postoperative parameters: $n(\%)$} \\
\hline Postoperative complications: $n(\%)$ & $2(7.1 \%)$ & $2(4.3)$ & 0.626 & $4(5.3)$ \\
\hline Postoperative first oral intake of fluids: postoperative day (range) & $0(0-1)$ & $0(0-1)$ & 0.899 & $0(0-1)$ \\
\hline Postoperative first oral intake of solid food: postoperative day (range) & $1(0-1)$ & $1(0-1)$ & 0.128 & $1(0-1)$ \\
\hline Postoperative opioid requirements: days (range) & $0.5(0-3)$ & $0(0-2)$ & 0.849 & $0(0-3)$ \\
\hline Postoperative stay: days (range) & $2(1-9)$ & $2(1-7)$ & 0.551 & $2(1-9)$ \\
\hline
\end{tabular}

Data are presented as median (range) or number $(\%)$

Table 6 Histopathologic data ${ }^{a}$

\begin{tabular}{lllll}
\hline Parameter & Group 1 $(n=28)$ & Group 2 $(n=47)$ & $p$ Value & Total $(n=75)$ \\
\hline Tumor-free margin resection: $n(\%)$ & $26(92.9)$ & $45(95.7)$ & 0.626 & $53(94.7)$ \\
Minimal distance from resection line to tumor tissue: mm (range) & $3(0-13)$ & $8(0-30)$ & 0.003 & $5(0-30)$ \\
Largest tumor size: mm (range) & $24(6-80)$ & $25(7-75)$ & 0.549 & $25(6-80)$ \\
Weight of resected specimen: g (range) & $38(5-174)$ & $52(7-270)$ & 0.635 & $44(5-270)$ \\
Largest dimension of resectat: mm (range) & $60(25-90)$ & $65(25-120)$ & 0.359 & $63(25-120)$ \\
\hline
\end{tabular}

${ }^{\mathrm{a}}$ Data are presented as median (range) or number (\%)

\section{Discussion}

Video laparoscopy has greatly changed the practice of contemporary surgery, conferring several benefits including minimal damage to the abdominal wall, faster recovery, fewer wound complications, and improved cosmetic results. Despite early skepticism concerning laparoscopic liver resection, it currently is accepted generally as a feasible alternative to open resection, also for cancer [29-31].

The current study demonstrated that laparoscopic liver resection can be performed safely for lesions located in both the anterolateral and posterosuperior segments by an experienced surgical team. We had a low rate of perioperative adverse events (a 5.3\% rate for intraoperative unfavorable accidents by the Satava approach and a 5.3\% rate for postoperative complications by the Accordion classification), and no conversion or mortality occurred in the analyzed groups.

Despite their relatively early introduction in 1992, laparoscopic techniques in liver surgery have not spread worldwide as broadly as, for example, laparoscopy for cholecystectomy [29, 30]. The majority of hepatobiliary centers perform only open surgery for liver lesions. In centers performing laparoscopic liver resection, operations for lesions located in posterosuperior segments, which considered to be so-called "difficult segments", are largely retained for open surgery.
For tumors located in segments 7 or 8 , nonanatomic liver resection or right posterior sectionectomy is preferable to right hemihepatectomy because it preserves the liver parenchyma. However, these procedures are more challenging technically. Although only a small volume of liver parenchyma usually is removed in a nonanatomic liver resection, these resections in segments 7 and 8 are technically difficult because exposure of deeply located lesions is intricate, and the transection plane can be rounded or angled [9, 19, 32]. Hanging techniques implying mobilization of the right liver lobe and dissection along the caval vein and up between the orifice of the right and the middle hepatic veins enabling to hang the right liver lobe could be of major assistance (personal communication, Dr. I. S.Tait, Dundee, UK).

In our series, the laparoscopic approach to posterosuperior segments was not associated with significant difficulties or increased morbidity. This perception is supported equally by both intra- and postoperative outcomes for resections of anterolateral and posterosuperior liver segments. Appropriate adjustment of trocar placement, a flexible laparoscope, extensive mobilization of the right liver lobe, and adequate use of the gravity force are of great help in such cases. In our experience, the availability of several high-resolution large monitors in the operative theater enabling surgeons to view not only intraoperative 
Fig. 3 Operative room environment. A Imaging with preoperative computed tomography. B Imaging with three-dimensional liver reconstruction
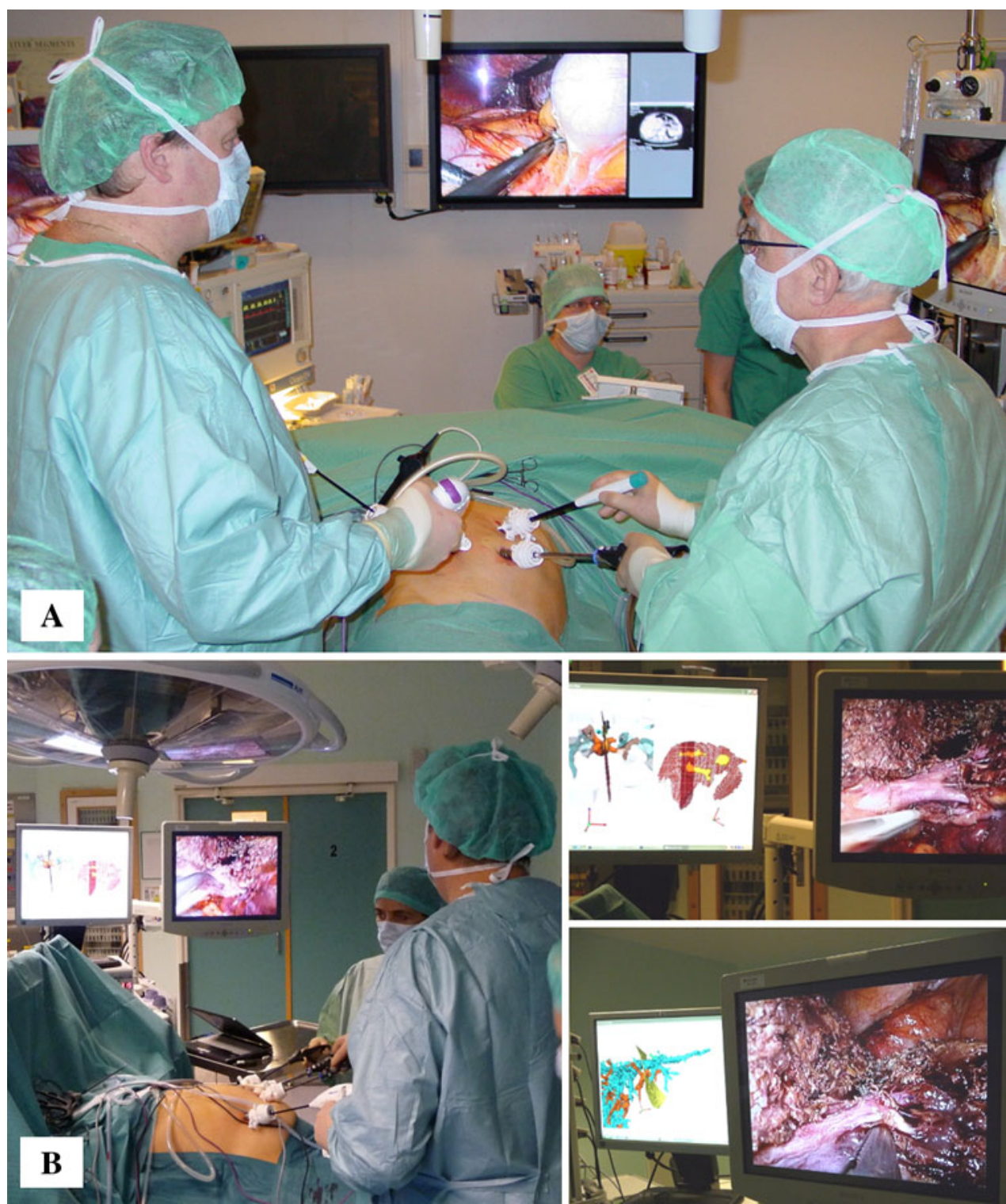

ultrasonography but also preoperative imaging including three-dimensional reconstruction of crucial anatomic structures (vessels and bile ducts) was of major help (Fig. 3). This further perks up intraoperative navigation and thus may play an important role in laparoscopic liver surgery, especially in the case of tumors located in posterosuperior segments [33, 34].

The minimal distance from resection line to tumor tissue was the only parameter that differed significantly between the studied groups. With regard to malignant liver lesions, we have always aimed to achieve resection with a sufficiently safe resection margin with respect to tumor location. However, the observed phenomenon may occur due to a poorer exposition of the operative field during the approach to tumors located in posterosuperior segments. This has led to increased concern with regard to possible vascular or biliary injury. Thus, the surgeon was constrained to perform resection closer to the tumor margin to prevent the additional risk while retaining a secure free margin.

In our series, this phenomenon did not lead to a higher rate of tumor-involved resection margins, to a higher rate of recurrence in the liver, or to a poorer survival in patients with resections of lesions located in posterosuperior segments.

Thoracoscopic access to approach segments 7 and 8 is suggested [35]. The thoracoscopic approach is associated with a longer operative time and opening of the thoracic cavity, consequently leading to increased risk of complications [36, 37]. This could indicate that application of the thoracoscopic approach is not impeccable. A recent publication from Japan stated that the authors had switched 
from the thoracoscopic to the laparoscopic approach for resection of lesions in segment 8 due to lack of appreciable benefits [38].

We used a totally laparoscopic rather than a handassisted approach as used by many others [39, 40]. With some other surgeons, we believe that the hand-assisted method or hybrid techniques have a limited role [9]. These techniques supply a tactile sensation that is lacking during laparoscopy. However, this approach requires a larger incision, which reduces the benefits of minimally invasive surgery. Besides, fatigue in the inserted hand and air leakage represent drawbacks of the hand-assisted method [41]. However a handport could be applied in very challenging situations and tumor locations when the surgeon does not achieve significant progress in the procedure or feels himself not fully confident without tactile control of resection.

The hand-assisted technique was applied in only two cases to facilitate extra-challenging resections in group 1 (7.1\%). None of the cases in group 2 required use of the hand-assisted technique. The decision to establish a handport was made during the procedure based on intraprocedural circumstances to reduce an expected unreasonably long operative time in case of application of the totally laparoscopic approach. The handport was established before liver mobilization in one case and after liver mobilization in another case.

Intraoperative ultrasonography could partly substitute for the lacking tactile sensation during totally laparoscopic resection. Therefore, its application during laparoscopic liver resection is mandatory to ensure adequate tumor identification and margin control [42, 43].

Theoretical premises and experimental studies have led to anxiety among clinicians concerning the potential risk for gas embolism during laparoscopic liver resection, which has been especially highlighted with regard to posterosuperior segments. This argument also has been used by supporters of hand-assisted techniques [44, 45]. However accumulated world experience has shown that this risk has been greatly overestimated [46, 47].

As for open surgery, bleeding and biliary leakage were regarded as the most serious complications in both groups [48]. However, high-tech surgical equipment has considerably contributed to reducing the hazard of such complications [49]. We experienced adequate hemostatic control by means of modern surgical equipment in both patient groups. The postoperative course was equal in the two groups. The median duration of postoperative stay was only 2 days. The vast majority of patients started to consume fluids on the day of the operation, and all the patients started to consume solid food on the first operative day in both groups.

\section{Conclusion}

Laparoscopic liver resection for lesions located in posterosuperior segments represents a certain technical challenge in contrast to anterolateral segments. However, appropriate adjustment of surgical techniques and patient positioning suited to the particular tumor location enables the laparoscopic technique to provide safe and effective parenchymasparing resections for lesions located in both posterosuperior and anterolateral segments. We recommend wide application of laparoscopic techniques for lesions located in posterosuperior segments for centers that have mastered laparoscopic liver resection of anterolateral segments with a high degree of confidence. This will enable provision of the best currently available treatment for a large number of patients, will favor parenchyma-sparing techniques, and will definitively contribute to further promotion of a patientfriendly concept of minimally invasive surgery.

Disclosures Airazat M. Kazaryan, Bård I. Røsok, Irina Pavlik Marangos, Arne R. Rosseland, and Bjørn Edwin have no conflicts of interest or financial ties to disclose.

Open Access This article is distributed under the terms of the Creative Commons Attribution Noncommercial License which permits any noncommercial use, distribution, and reproduction in any medium, provided the original author(s) and source are credited.

\section{References}

1. Edwin B, Nordin A, Kazaryan AM (2011) Laparoscopic liver surgery: new frontiers. Scand J Surg 100:54-65

2. Reich H, McGlynn F, DeCaprio J, Budin R (1991) Laparoscopic excision of benign liver lesions. Obstet Gynecol $78(5$ pt 2): 956-958

3. Gagner M, Rheault M, Dubuc J (1992) Laparoscopic partial hepatectomy for liver tumor. Surg Endosc 6:99

4. Azagra JS, Goergen M, Gilbart E, Jacobs D (1996) Laparoscopic anatomical (hepatic) left lateral segmentectomy-technical aspects. Surg Endosc 10:758-761

5. Buell JF, Thomas MT, Rudich S, Marvin M, Nagubandi R, Ravindra KV, Brock G, McMasters KM (2008) Experience with more than 500 minimally invasive hepatic procedures. Ann Surg 248:475-486

6. Cai XJ, Yang J, Yu H, Liang X, Wang YF, Zhu ZY, Peng SY (2008) Clinical study of laparoscopic versus open hepatectomy for malignant liver tumors. Surg Endosc 22:2350-2356

7. Chen HY, Juan CC, Ker CG (2008) Laparoscopic liver surgery for patients with hepatocellular carcinoma. Ann Surg Oncol 15: 800-806

8. Cherqui D, Husson E, Hammoud R, Malassagne B, Stephan F, Bensaid S, Rotman N, Fagniez PL (2000) Laparoscopic liver resections: a feasibility study in 30 patients. Ann Surg 232: 753-762

9. Dagher I, Proske JM, Carloni A, Richa H, Tranchart H, Franco D (2007) Laparoscopic liver resection: results for 70 patients. Surg Endosc 21:619-624 
10. Edwin B, Mala T, Gladhaug I, Fosse E, Mathisen Y, Bergan A, Soreide O (2001) Liver tumors and minimally invasive surgery: a feasibility study. J Laparoendosc Adv Surg Tech A 11:133-139

11. Gagner M, Rogula T, Selzer D (2004) Laparoscopic liver resection: benefits and controversies. Surg Clin North Am 84:451-462

12. Gayet B, Cavaliere D, Vibert E, Perniceni T, Levard H, Denet C, Christidis C, Blain A, Mal F (2007) Totally laparoscopic right hepatectomy. Am J Surg 194:685-689

13. Ito K, Ito H, Are C, Allen PJ, Fong Y, Dematteo RP, Jarnagin WR, D'Angelica MI (2009) Laparoscopic versus open liver resection: a matched-pair case control study. J Gastrointest Surg $13: 2276-2283$

14. Kazaryan AM, Pavlik MI, Rosseland AR, Rosok BI, Mala T, Villanger O, Mathisen O, Giercksky KE, Edwin B (2010) Laparoscopic liver resection for malignant and benign lesions: tenyear Norwegian single-center experience. Arch Surg 145:34-40

15. Koffron AJ, Auffenberg G, Kung R, Abecassis M (2007) Evaluation of 300 minimally invasive liver resections at a single institution: less is more. Ann Surg 246:385-392

16. Lee KF, Cheung YS, Chong CN, Tsang YY, Ng WW, Ling E, Wong J, Lai PB (2007) Laparoscopic versus open hepatectomy for liver tumours: a case control study. Hong Kong Med J 13:442-448

17. Mala T, Edwin B, Rosseland AR, Gladhaug I, Fosse E, Mathisen O (2005) Laparoscopic liver resection: experience of 53 procedures at a single center. J Hepatobiliary Pancreat Surg 12:298-303

18. Rau HG, Meyer G, Cohnert TU, Schardey HM, Jauch K, Schildberg FW (1995) Laparoscopic liver resection with the water-jet dissector. Surg Endosc 9:1009-1012

19. Vibert E, Perniceni T, Levard H, Denet C, Shahri NK, Gayet B (2006) Laparoscopic liver resection. Br J Surg 93:67-72

20. Vigano L, Tayar C, Laurent A, Cherqui D (2009) Laparoscopic liver resection: a systematic review. J Hepatobiliary Pancreat Surg 16:410-421

21. Laurent A, Cherqui D, Lesurtel M, Brunetti F, Tayar C, Fagniez PL (2003) Laparoscopic liver resection for subcapsular hepatocellular carcinoma complicating chronic liver disease. Arch Surg 138:763-769

22. Cho JY, Han HS, Yoon YS, Shin SH (2008) Feasibility of laparoscopic liver resection for tumors located in the posterosuperior segments of the liver, with a special reference to overcoming current limitations on tumor location. Surgery 144:32-38

23. Kazaryan AM, Marangos IP, Rosok BI, Rosseland AR, Villanger O, Fosse E, Mathisen O, Edwin B (2010) Laparoscopic resection of colorectal liver metastases: surgical and long-term oncologic outcome. Ann Surg 252:1005-1012

24. Satava RM (2005) Identification and reduction of surgical error using simulation. Minim Invasive Ther Allied Technol 14:257-261

25. Dindo D, Demartines N, Clavien PA (2004) Classification of surgical complications: a new proposal with evaluation in a cohort of 6,336 patients and results of a survey. Ann Surg 240: 205-213

26. Strasberg SM, Linehan DC, Hawkins WG (2009) The accordion severity grading system of surgical complications. Ann Surg 250:177-186

27. Porembka MR, Hall BL, Hirbe M, Strasberg SM (2010) Quantitative weighting of postoperative complications based on the accordion severity grading system: demonstration of potential impact using the American College of Surgeons National Surgical Quality Improvement Program. J Am Coll Surg 210:286-298

28. Edwin B, Rosseland AR, Færden AE, Størkson R, Reiertsen O, Trondsen E, Engen J (1995) Open technique in creating pneumoperitoneum. Scand J Gastroenterol 30(Suppl 209):17

29. Buell JF, Cherqui D, Geller DA, O'Rourke N, Iannitti D, Dagher I, Koffron AJ, Thomas M, Gayet B, Han HS et al (2009) The international position on laparoscopic liver surgery: The Louisville Statement, 2008. Ann Surg 250:825-830
30. Marvin MR, Buell JF (2009) Laparoscopic liver surgery. Adv Surg 43:159-173

31. Nguyen KT, Gamblin TC, Geller DA (2008) Laparoscopic liver resection for cancer. Future Oncol 4:661-670

32. Sandler A, Kimura K, Soper R (2001) Nonanatomic hepatic resection with a pledgetted suturing technique. J Pediatr Surg 36: 209-212

33. Lamata P, Lamata F, Sojar V, Makowski P, Massoptier L, Casciaro S, Ali W, Studeli T, Declerck J, Elle OJ, et al (2010) Use of the Resection Map System as guidance during hepatectomy. Surg Endosc 24:2327-2337

34. Lango T, Tangen GA, Marvik R, Ystgaard B, Yavuz Y, Kaspersen JH, Solberg OV, Hernes TA (2008) Navigation in laparoscopy-prototype research platform for improved image-guided surgery. Minim Invasive Ther Allied Technol 17:17-33

35. Teramoto K, Kawamura T, Takamatsu S, Noguchi N, Nakamura N, Arii S (2003) Laparoscopic and thoracoscopic partial hepatectomy for hepatocellular carcinoma. World J Surg 27:11311136

36. Huang MT, Wei PL, Wang W, Li CJ, Lee YC, Wu CH (2009) A series of laparoscopic liver resections with or without HALS in patients with hepatic tumors. J Gastrointest Surg 13:896-906

37. Tsuchiya M, Otsuka Y, Tamura A, Nitta H, Sasaki A, Wakabayashi G, Kaneko H (2009) Status of endoscopic liver surgery in Japan: a questionnaire survey conducted by the Japanese Endoscopic Liver Surgery Study Group. J Hepatobiliary Pancreat Surg 16:405-409

38. Sasaki A, Nitta H, Otsuka K, Takahara T, Nishizuka S, Wakabayashi G (2009) Ten-year experience of totally laparoscopic liver resection in a single institution. Br J Surg 96:274-279

39. Poultsides G, Brown M, Orlando R III (2007) Hand-assisted laparoscopic management of liver tumors. Surg Endosc 21:12751279

40. Robles R, Marin C, Abellan B, Lopez A, Pastor P, Parrilla P (2008) A new approach to hand-assisted laparoscopic liver surgery. Surg Endosc 22:2357-2364

41. Dulucq JL, Wintringer P, Stabilini C, Berticelli J, Mahajna A (2005) Laparoscopic liver resections: a single-center experience. Surg Endosc 19:886-891

42. Mala T, Edwin B, Gladhaug I, Fosse E, Soreide O, Bergan A, Mathisen $O$ (2002) A comparative study of the short-term outcome following open and laparoscopic liver resection of colorectal metastases. Surg Endosc 16:1059-1063

43. Santambrogio R, Opocher E, Ceretti AP, Barabino M, Costa M, Leone S, Montorsi M (2007) Impact of intraoperative ultrasonography in laparoscopic liver surgery. Surg Endosc 21:181-188

44. Jayaraman S, Khakhar A, Yang H, Bainbridge D, Quan D (2009) The association between central venous pressure, pneumoperitoneum, and venous carbon dioxide embolism in laparoscopic hepatectomy. Surg Endosc 23:2369-2373

45. Schmandra TC, Mierdl S, Hollander D, Hanisch E, Gutt C (2004) Risk of gas embolism in hand-assisted versus total laparoscopic hepatic resection. Surg Technol Int 12:137-143

46. Gagner M (2010) Small incision, big surgeon: laparoscopic liver resection for tumors without a doubt: Comment on "Laparoscopic Liver Resection for Malignant and Benign Lesions: TenYear Norwegian Single-Center Experience. Arch Surg 145:40-41

47. Nguyen KT, Gamblin TC, Geller DA (2009) World review of laparoscopic liver resection-2,804 patients. Ann Surg 250:831-841

48. Erdogan D, Busch OR, Gouma DJ, van Gulik TM (2009) Morbidity and mortality after liver resection for benign and malignant hepatobiliary lesions. Liver Int 29:175-180

49. Poon RT (2007) Current techniques of liver transection. HPB Oxford 9:166-173 